\title{
Tumors of the lateral ventricles: a clinico-pathological study
}

\author{
Ojha $S^{1}$, Fernandes $G^{2}$, Shenoy $A^{3}$ \\ ${ }^{1}$ Dr Sandeep Ojha, Assistant professor, Department of Pathology, Chirayu Medical College and Hospital Bhopal, ${ }^{2}$ Dr \\ Gwendolyn Fernandes, Associate Professor, Department of Pathology, Seth G.S Medical College and KEM Hospital \\ Mumbai, ${ }^{3}$ Dr Asha Shenoy, Professor Department of Pathology, Seth G.S Medical College and KEM Hospital Mumbai
}

Address for correspondence: Dr Sandeep Ojha, Email: roshanchanchlani@gmail.com

\begin{abstract}
Introduction: Brain tumors are rare compared to other fatal and life-diminishing diseases and its incidence is increasing. The objective is to study the lateral ventricular tumors with reference to age groups, gender, anatomical location, the histopathological features including the histological grades, and the clinico- radio- pathological correlation of the above cases. Methodology: Retrospective analysis of tumors of the lateral ventricle of the CNS diagnosed in the department of Neuropathology at a tertiary care and referral hospital, from January 2001 to June 2009. Results: Average Incidence of primary lateral ventricular tumor was $1.6 \%$, that tumor involve the left lateral ventricle $(46.3 \%)$ more commonly than the right lateral ventricle (29.9\%). Commonest tumors in our study were the Neuronal and mixed glioneuronal tumors [31\%]. $78.1 \%$ of the lateral ventricular tumors were correctly diagnosed on radiology. Conclusion: Commonest tumors were Neuronal and mixed glioneuronal tumors. Most of the tumors belonged to low WHO grade. Fairly good correlation was found between radiological and histopathological diagnosis.
\end{abstract}

Keywords: Histopathology, Lateral ventricles, Radiology, Tumors.

\section{Introduction}

Brain tumors are rare as compared with other fatal and life-diminishing diseases and incidence has increased over the last 20 years in all age groups, both overall and for specific histologies. Brain tumors account for a small proportion of all cancers $(1.4 \%)$ and cancerrelated deaths $(2.4 \%)$. The incidence of primary central nervous system (CNS) neoplasm in adults has been reported to be from 11 to 12 per 100,000 [1, 2]. Tumors of the lateral ventricles can be either primary intraventricular tumors [3], when they develop from the ventricular lining (i.e., the ependyma and subependymal glia), from the epithelium of the choroid plexus and its arachnoid supporting tissue, or from misplaced tissue or "secondary" or paraventricular tumors when they develop from the brain parenchyma and more than two thirds of their surface bulges into the lateral ventricle [4]. Most lateral ventricular tumors are histologically benign or have slow growth potential [5]. As these tumors grow slowly within the ventricles, they either obstruct normal CSF flow, leading to hydrocephalus and resulting signs and symptoms of increased

Manuscript received: $25^{\text {th }}$ Sept 2015

Reviewed: $10^{\text {th }}$ Oct 2015

Author Corrected: $17^{\text {th }}$ Oct 2015

Accepted for Publication: $26^{\text {th }}$ Oct 2015 intracranial pressure (ICP), or they compress the adjacent structures, causing a focal neurologic deficit. This retrospective analytical study was conducted in a Neuropathology laboratory at a tertiary care and referral centre. The centre caters to around 10,000 out patients and 5,500 indoor patients annually in the Neurosurgery department alone. The present study is a retrospective analysis of around 100 tumors of CNS occurring purely in lateral ventricles, diagnosed over a period of 8.5 years from January 2001 to June 2009 in the Neuropathology Laboratory of a tertiary care and referral centre. The objective is to study the lateral ventricular tumors with reference to age- groups, gender, anatomical location, the histopathological features including the histological grades, and the clinico- radio- pathological correlation of the above cases.

\section{Material and Methods}

The institutional ethical committee approval was sought. This study is a retrospective analysis of tumors of the lateral ventricle of the CNS diagnosed in the department of Neuropathology at a tertiary care and 
referral hospital, from January 2001 to June 2009 - a period of eight and a half years.

Surgical specimens and biopsy tissues received were fixed overnight in $10 \%$ buffered formalin and submitted for processing. Paraffin sections were cut at 4-6 microns thickness and routine $\mathrm{H} \& \mathrm{E}$ staining was performed. Special stains like PAS, Reticulin etc. were performed whenever necessary. The clinical, radiological and therapeutic data was obtained from patients' original case paper records. The results of the blocks of few patients, submitted for immunohistochemistry were also obtained. The latest, WHO classification of tumors of Central Nervous system and WHO grading system for tumors of the Central nervous system (4th edition) published in 2007, was used. Primary tumors of the lateral ventricles are more common than its secondary involvement, and we have excluded all secondary Intra-ventricular tumors in our study. A total of 97 cases of primary tumors of the lateral ventricles were reported during the above period.
The data was entered and analyzed in Microsoft office excel 2007. Qualitative data was summarized as percentage and proportions.

\section{Result}

A total of 97 cases of primary tumors of the lateral ventricles were analyzed. Most lateral ventricular tumors $(\sim 50 \%)$ occur in $2^{\text {nd }}$ and $3^{\text {rd }}$ decade, of which most occur in $3^{\text {rd }}$ decade $(\sim 30 \%)$. Incidence is low at extremes of ages. Nearly $80 \%$ of patients presents with signs and symptoms of raised intracranial tension. Headache was the presenting symptom in most of the tumors (82.4\%). (Fig No 1) Most patients present with cranial nerve deficits, ataxia and gait disturbances. Convulsions and personality changes are also amongst significant findings associated with lateral ventricular tumors. (Table no. 1) For purpose of simplicity all lesions were classified into 10 major groups as depicted in (Table No. 2). Incidence of individual tumors amongst total brain tumors received in our institute is shown in Table No 3.

Fig No. 1 Pie chart showing presenting symptoms

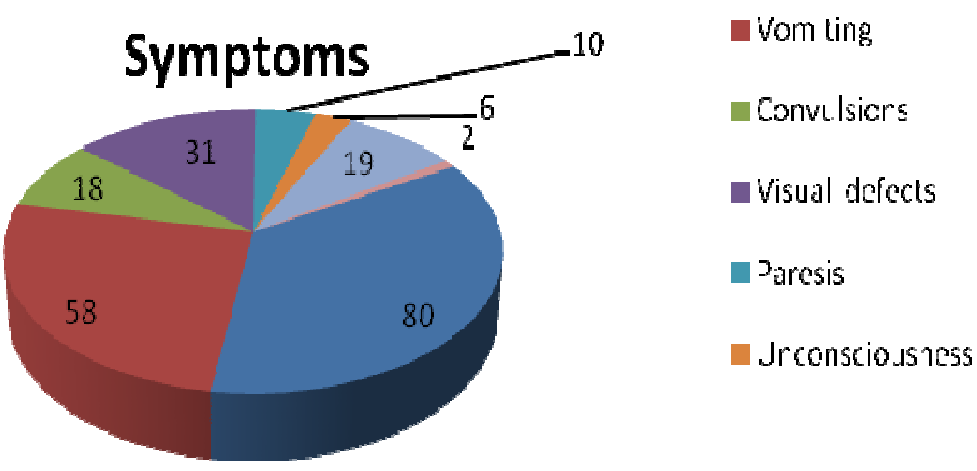

Table 1: Clinical presentations

\begin{tabular}{|l|l|l|}
\hline Signs & No. of Cases(n=97) & Percentage \\
\hline Papilloedema & 7 & $7.20 \%$ \\
\hline Cranial nerve palsy & 14 & $14.40 \%$ \\
\hline Optic atrophy & 3 & $3.10 \%$ \\
\hline Ataxia & 12 & $12.40 \%$ \\
\hline Focal neurological deficit & 7 & $7.20 \%$ \\
\hline Associated with other systemic diseases & 5 & $5.20 \%$ \\
\hline Recurrences & 2 & $2.10 \%$ \\
\hline
\end{tabular}

Table No 2: Categorization of Tumors 


\begin{tabular}{|l|l|l|}
\hline Group of Tumor & No. of Cases $(\mathbf{n = 9 7})$ & Percentage \\
\hline Neuronal and mixed glioneuronal tumors & 31 & $31.90 \%$ \\
\hline Meningeal tumors & 15 & $15.50 \%$ \\
\hline SEGA & 12 & $12.30 \%$ \\
\hline Ependymal tumors & 6 & $6.20 \%$ \\
\hline Other Astrocytic neoplasms & 15 & $15.40 \%$ \\
\hline Choroid plexus tumors & 10 & $10.30 \%$ \\
\hline Embryonal tumors & 4 & $4.10 \%$ \\
\hline NHL & 2 & $2.10 \%$ \\
\hline Metastasis & 1 & $1.03 \%$ \\
\hline Germ cell tumors (Teratoma) & 1 & $1.03 \%$ \\
\hline
\end{tabular}

Table No 3: Incidence of individual tumors amongst total brain tumors received in our institute

\begin{tabular}{|c|c|c|}
\hline Tumor & No. of cases $(n=6078)$ & $\%$ \\
\hline \multicolumn{3}{|l|}{ Neuronal and mixed glioneuronal tumors: } \\
\hline Central neurocytoma & 30 & $0.40 \%$ \\
\hline Ganglioneurocytoma & 1 & $0.01 \%$ \\
\hline Total & 31 & $0.50 \%$ \\
\hline \multicolumn{3}{|l|}{ Meningeal tumors:- } \\
\hline Transitional meningioma & 8 & $0.13 \%$ \\
\hline Fibroblastic meningioma & 3 & $0.04 \%$ \\
\hline Meningothelial meningioma & 3 & $0.04 \%$ \\
\hline Atypical meningioma & 1 & $0.01 \%$ \\
\hline Total & 15 & $0.25 \%$ \\
\hline Subependymal giant cell astrocytoma (SEGA) & 12 & $0.20 \%$ \\
\hline \multicolumn{3}{|l|}{ Ependymal tumors: - } \\
\hline Ependymoma & 3 & $0.04 \%$ \\
\hline Subependymoma & 3 & $0.04 . \%$ \\
\hline Total & 6 & $0.09 \%$ \\
\hline \multicolumn{3}{|l|}{ Other glial tumors:- } \\
\hline Pilocytic astrocytoma & 2 & $0.03 \%$ \\
\hline Grade 2 astrocytoma & 4 & $0.06 \%$ \\
\hline Grade 3 astrocytoma & 3 & $0.04 \%$ \\
\hline Grade 4 astrocytoma & 6 & $0.09 \%$ \\
\hline Total & 15 & $0.25 \%$ \\
\hline \multicolumn{3}{|l|}{ Choroid plexus tumors: - } \\
\hline Choroid plexus papilloma & 8 & $0.13 \%$ \\
\hline Choroid plexus carcinoma & 2 & $0.03 \%$ \\
\hline Total & 10 & $0.16 \%$ \\
\hline \multicolumn{3}{|l|}{ Embryonal tumors: - } \\
\hline Premitive neuroectodermal tumor & 3 & $0.04 \%$ \\
\hline Medulloepithelioma & 1 & $0.01 \%$ \\
\hline Total & 4 & $0.06 \%$ \\
\hline Non Hodgkin’s lymphoma & 2 & $0.03 \%$ \\
\hline Metastases & 1 & $0.01 \%$ \\
\hline Germ cell tumors (Teratoma) & 1 & $0.01 \%$ \\
\hline Total & 97 & $1.60 \%$ \\
\hline
\end{tabular}


In our study, we found out that tumor involve the left lateral ventricle $(46.3 \%)$ more commonly than the right lateral ventricle $(29.9 \%)$. There was a male preponderance with male to female ratio of 1.6:1. Male preponderance is seen in nearly all age groups except in infants. Most lateral ventricular tumours occur in the $2^{\text {nd }}$ and $3^{\text {rd }}$ decade $(\sim 50 \%)$ with decreasing incidences in the extremes of life. In first decade of life choroid plexus tumors are most common ( 64\%), of which choroid plexus papilloma includes majority of cases.

Mature teratoma, NHL and metastasis are not graded by WHO grading system for CNS tumors and this was not included (Table No. 4). Most of the lateral ventricular tumors are of low grade in younger age group. In adults, in 4th, 5th decade or more, low grade tumors are common with increase in incidence of higher grade tumors (grade3 or grade4). Higher grade tumors are more common in males. Neuronal and mixed glioneuronal tumors [31.9\%] were most common lateral ventricular tumors followed by meningioma [15.5\%], and Subependymal giant cell astrocytoma [12.3\%]. Transitional meningioma [8.2\%] is most common type amongst the meningiomas. Choroid plexus papilloma is most common amongst choroid plexus tumors. Grade 3 [3.1\%] and grade 4 [6.2\%] tumors are more common than low grade astrocytoma excluding Subependymal giant cell astrocytoma. Calcification was seen in total 26 tumors. Necrosis observed in 13 tumors. Invasion of brain parenchyma was seen in 10 tumors. Mitosis identified in 14 tumors and Endothelial microvascular proliferation was seen in 6 tumors.

Table No. 4. Grading of the tumors (WHO Grading (2007)

\begin{tabular}{|l|l|l|}
\hline WHO GRADE & No. of cases(n=93)* & Percentage \\
\hline Grade I & 40 & $43 \%$ \\
\hline Grade II & 38 & $40.90 \%$ \\
\hline Grade III & 5 & $5.40 \%$ \\
\hline Grade IV & 10 & $10.70 \%$ \\
\hline
\end{tabular}

* 4 cases excluded, as they are not classified in WHO grade

Radiological diagnosis was given in total 82 of 97 cases $(84.5 \%)$ and in 15 patients no definitive diagnosis was given. All meningiomas and Grade IV astrocytoma were correctly diagnosed during follow up. All 3 Subependymomas were not picked up on radiology. $74.2 \%$ cases of central neurocytomas were correctly diagnosed and 2 of the 3 misdiagnosed tumors were confused with Gliomas. Most of the SEGA (66.6\%) and choroid plexus papilloma (87.5\%) were correctly diagnosed.

In our study gross total excision was achieved in $61.9 \%$ of operated cases (44/71 cases), subtotal excision done in $11.2 \%$ cases, radical excision in $7 \%$, near total excision in $12.7 \%$ and partial excision done in $5.6 \%$ of cases, decompression treatment was done in $1.4 \%$. In rest $26.8 \%$ of cases biopsy of tumor was done. Overall surgical mortality rate in early post operative period in our study is found out to be $2.8 \%$ of total 71 cases operated. In early post operative period in $73.8 \%$ patient, symptoms and signs was improved and $26.7 \%$ patients who were operated had surgical complication in the form of additional neurological deficits $(9.8 \%)$, Convulsion (1.4\%) Cerebral infarction (1.4\%) Meningitis (1.4\%) and Intraventricular hemorrhage
(2.8\%). Residual tumor (12.6\%) was seen in 5 central neurocytomas, 1 Choroid plexus carcinoma 1 SEGA and 2 other astrocytomas. Prognosis is usually good in most of the tumors and early post op period is uneventful in most.

\section{Discussion}

Brain tumors are rare compared to other fatal and lifediminishing diseases and incidence has increased over the last 20 years in all age groups for both overall and for specific histologies. Tumors involving lateral ventricles are uncommon neoplasms of the brain comprising of $0.8 \%$ to $1.6 \%$ of all brain tumors [4-6]. The average incidence of primary lateral ventricular tumors at our institution is $1.6 \%$ of total 6078 tumors received and $22.9 \%$ of total Intraventricular tumors received. This is comparable to study done by Hamit Z Gokalp et al on 112 patients with their incidence of $1.5 \%$ [ 6 ]. Mean patient age was found out to be 27.4 years (range 2 months to 72 years). Similarly, independently Halil ibrahim et al [7] and D'Angelo VA et al[8]had found that the mean age at presentation was 36 (range 2-71 years) and 39 years respectively. In our study also there is a male preponderance with male to female ratio as 1.6:1 with 60 males and 37 females. 
Male preponderance is seen in all tumors except in Meningioma. Jelinek et al, Halil Ibrahim et al and Gokulp et al found male to female ratio as 1.2:1, 1.3:1 and 1.7:1 respectively $[6,7,9]$. In our study, we found out that tumor involves left lateral ventricle more commonly than right lateral ventricle. Tumors which primarily involve left lateral ventricle 44/97 tumors (45.3\%). Tumors involving right lateral ventricle primarily: - 31/97 tumors (31.9\%). Tumors arising from both lateral ventricles: $22.7 \%$. Central neurocytoma, Meningiomas except Fibroblastic type, Choroid plexus papilloma, Grade 2 Astrocytoma, Ependymoma and Subependymoma are more common on left side while Fibroblastic Meningioma, Choroid plexus carcinoma and Pilocytic Astrocytoma are more common on right side. Central neurocytoma and Astrocytoma are the most common tumors involving both ventricles.

According to study done by Gokalp et al [ 6] the most frequently seen clinical symptoms and signs were papilloedema $(42.9 \%)$, headache $(35.7 \%)$, motor disturbance $(25 \%)$, sensory disturbance $(25 \%)$, nausea and vomiting $(22.3 \%)$, vision field defect (17.8\%), and loss of vision $(17.8 \%)$. Mental changes without additional neurological signs or symptoms were found in $17.8 \%$ of the cases. Epileptic seizures $(13.4 \%)$ and head enlargement $(8.9 \%)$ were infrequent. Our study is thus, comparable to literature and findings in other studies with signs and symptoms of raised intracranial tension as most common presenting features. In our study Neuronal and mixed glioneuronal tumors [31.9\%] were most common followed by meningioma [15.5\%], and Subependymal giant cell astrocytoma [12.3\%]. Choroid plexus papilloma $(8.2 \%)$ and choroid plexus carcinoma $(2.1 \%)$ are the common neoplasms amongst choroid plexus tumors. Other glial neoplasms include Pilocytic astrocytoma (2.1\%), Grade 2 Astrocytoma (4.1\%), Grade 3 Astrocytoma [3.1\%] and Grade 4 Astrocytoma [6.2\%]. Other tumors include Ependymoma (3.1\%), Subependymoma (3.1\%), Embryonal tumors $(4.1 \%)$, Teratoma (1.03\%), Non Hodgkin's lymphoma (2.1\%), and Metastasis (1.03\%). 78 of 93 of our tumors were low grade as per WHO criteria. This amounts to $84 \%$ of all tumors. Similar results has been reported by other studies in other part of the world $[6,7,8,9]$.

Overall surgical mortality rate in early post operative period in our study was found to be $2.8 \%$ of total 71 cases operated and all were due to intraventricular hemorrhage, which are similar to study conducted by Gokalp et al.[6]

\section{Conclusion}

Average Incidence of primary lateral ventricular tumor was $1.6 \%$ and had male preponderance. Commonest tumors were Neuronal and mixed glioneuronal tumors. Most of the tumors belonged to low WHO grade. Radiological findings were found to be highly consistent with histological typing of the tumor and a fairly good correlation was found between radiological and histopathological diagnosis. Most common surgical procedure done for lateral ventricular tumors was gross total excision.

\section{Funding: Nil,Conflict of interest: None. Permission of IRB: Yes}

\section{References}

1. Surawicz TS, Davis F, Freels S, Laws ER Jr, Menck HR. Brain tumor survival: results from the National Cancer Data Base. J Neurooncol. 1998 Nov;40(2):15160.

2. Deorah S, Lynch CF, Sibenaller ZA, Ryken TC. Trends in brain cancer incidence and survival in the United States: Surveillance, Epidemiology, and End Results Program, 1973 to 2001. Neurosurg Focus. 2006 Apr 15;20(4):E1.

3. Koeller KK, Sandberg GD; Armed Forces Institute of Pathology. From the archives of the AFIP. Cerebral intraventricular neoplasms: radiologic-pathologic correlation. Radiographics. 2002 Nov-Dec;22(6):1473505 .

4. Pendl G, Oztürk E, Haselsberger K. Surgery of tumours of the lateral ventricle. Acta Neurochir (Wien). 1992;116(2-4):128-36.

5. Delfini R, Acqui M, Oppido PA, Capone R, Santoro A, Ferrante L. Tumors of the lateral ventricles. Neurosurg Rev. 1991;14(2):127-33.

6. Gökalp HZ, Yüceer N, Arasil E, Deda H, Attar A, Erdoğan A, Egemen N, Kanpolat Y. Tumours of the lateral ventricle. A retrospective review of 112 cases operated upon 1970-1997. Neurosurg Rev. 1998;21(23):126-37.

7. Seçer HI, Düz B, Izci Y, Tehli O, Solmaz I, Gönül E. Tumors of the lateral ventricle: the factors that affected the preference of the surgical approach in 46 patiens. Turk Neurosurg. 2008 Oct;18(4):345-55. 
8. D'Angelo VA, Galarza M, Catapano D, Monte

$\mathrm{V}$, Bisceglia M, Carosi I.

Lateral ventricle tumors: surgical strategies according to tumor origin and development--a series of 72 cases. Neurosurgery. 2005 Jan;56(1 Suppl):36-45; discussion 36-45.
9. Jelinek J, Smirniotopoulos JG, Parisi JE, Kanzer M. Lateral ventricular neoplasms of the brain: differential diagnosis based on clinical, CT, and MR findings. AJNR Am J Neuroradiol 1990; 11: 567-574.

\section{How to cite this article?}

Ojha S, Fernandes G, ShenoyA. Tumors of the lateral ventricles: a clinico-pathological study. Int J Med Res Rev 2015;3(10):1118-1123. doi: 10.17511/ijmrr.2015.i10.216. 